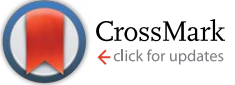

Cite this: RSC Adv., 2015, 5, 64983

\title{
Rapid adsorption removal of arsenate by hydrous cerium oxide-graphene composite $\uparrow$
}

\author{
Ling $\mathrm{Yu}{ }^{\mathrm{a}}$ Ying $\mathrm{Ma},{ }^{\mathrm{b}}$ Choon Nam Ong, ${ }^{a}$ Jianping $\mathrm{Xie}^{\mathrm{b}}$ and Yanbiao Liu${ }^{* a}$
}

Arsenic contamination has posed a health risk to millions of people around the world. In this study, a novel adsorbent, hydrous cerium oxide modified graphene (GNP-HCO), was synthesized for arsenic removal from aqueous solution. In the kinetics study, $>88 \%$ of the equilibrium adsorption capacity of arsenate $(\mathrm{As}(\mathrm{V}))$ can be achieved within the initial $20 \mathrm{~min}$. Such a rapid adsorption rate showed its promising potential towards actual application. The experimental data was better described by the Langmuir isotherm model, and the maximum adsorption capacities were 62.33 and $41.31 \mathrm{mg}$ - $\mathrm{As} \mathrm{g}^{-1}$ at $\mathrm{pH} 4.0$ and 7.0, respectively, which are much higher than many modified carbon-based adsorbents previously reported. Phosphate appeared to be the most severe competitive interferent on arsenic adsorption. Furthermore, the adsorptive removal of arsenic from surface water matrix was also evaluated and the results demonstrated that only $15 \mathrm{mg} \mathrm{L}^{-1}$ adsorbent was required to reduce the arsenic concentration from $100 \mu \mathrm{g} \mathrm{L}^{-1}$ to $<10 \mu \mathrm{g} \mathrm{L}^{-1}$. X-ray photoelectron spectroscopy (XPS) analysis indicated that the major chemical state of cerium (Ce) element in the adsorbent was +IV and the hydroxyl group might be involved in the adsorption process.

Received 13th May 2015

Accepted 23rd July 2015

DOI: $10.1039 / \mathrm{c} 5 \mathrm{ra0} 8922 \mathrm{k}$

www.rsc.org/advances explored towards arsenic removal. Of these adsorbents, metal oxides especially rare earth metal oxides have attracted much attention due to their excellent adsorption performance in removing anionic contaminants (e.g. arsenic). An ideal arsenic adsorbent should possess several advantages such as rapid adsorption kinetics, high adsorption capacity, excellent stability and strong affinity towards arsenic. Nevertheless, despite significant progress in the arsenic adsorption achieved to date, there are still some practical limitations to be addressed.

To overcome these limitations, researchers have been trying to develop composite adsorbents to combine the advantages of both. ${ }^{17}$ For example, metal oxides have been impregnated onto the surface of other porous carbon materials, such as activated carbon, for adsorptive removal of various organic compounds from water. ${ }^{18-20}$ It hence can be envisaged that composite adsorbent could combine the advantages of the carbon materials with high specific surface and suitable metal oxides with high affinity to arsenic.

Graphene, a 2D one-atom-thick layer of graphite, has attracted much attention recently due to its amazing properties. $^{21,22}$ It has been widely used in organic pollutants removal, ${ }^{23,24}$ energy storage devices, ${ }^{25}$ flexible transparent electrodes, ${ }^{26}$ solar cells, ${ }^{27}$ and electronics and optoelectronics. ${ }^{28}$ However, less attention has been paid to the adsorptive removal of inorganic pollutants such as arsenic by graphene or graphene-based composites. In this study, a novel and highperformance hydrous cerium oxide (HCO) modified graphene nanoplatelets (GNP) composite was developed to address the key limitations of slow adsorption kinetics for arsenic removal.
${ }^{a}$ NUS Environmental Research Institute, National University of Singapore, 5A Engineering Drive 1, \#02-01, 117411, Singapore.E-mail: eriliuyb@nus.edu.sg; Fax: +65 6872 1320; Tel: +6565167386

${ }^{b}$ Department of Chemical and Biomolecular Engineering, National University of Singapore, 117585, Singapore

$\uparrow$ Electronic supplementary information (ESI) available. See DOI: $10.1039 / \mathrm{c} 5 \mathrm{ra0} 08922 \mathrm{k}$ 
Over here, a facile wet-chemistry route was used to coat HCO onto the GNP surface. Various advanced characterization techniques (e.g. FESEM, EDS, and XPS) were adopted to study the morphological and compositional information of the assynthesized adsorbents. Adsorption kinetics and isotherm studies were comparatively conducted and the effect of solution $\mathrm{pH}$, natural organic matter (NOM) and competitive anions on the adsorption performance were systematically studied. The adsorptive removal of arsenic in surface water samples was carried out as well to further validate the effectiveness of the adsorbent, and the possible mechanisms involved were discussed.

\section{Material and methods}

\section{Materials}

The chemicals including $\mathrm{Ce}\left(\mathrm{NO}_{3}\right)_{3} \cdot 6 \mathrm{H}_{2} \mathrm{O}, \mathrm{Na}_{2} \mathrm{HAsO}_{4} \cdot 7 \mathrm{H}_{2} \mathrm{O}$, $\mathrm{Na}_{2} \mathrm{SO}_{4}, \mathrm{NaHCO}_{3}, \mathrm{NaF}, \mathrm{KH}_{2} \mathrm{PO}_{4}, \mathrm{NaOH}, \mathrm{HNO}_{3}$ and ethanol were of analytical grade and purchased from Sigma-Aldrich (St. Louis, MO) without further purification. Humic acid (HA) used to represent typical natural organic matter (NOM) in this study was purchased from Sigma-Aldrich (Product Number: H16752). C-grade graphene nanoplatelets (GNP) were purchased from XG Sciences (Lansing, MI). The stock solution of arsenate was prepared by dissolving a certain amount of $\mathrm{Na}_{2} \mathrm{HAsO}_{4} \cdot 7 \mathrm{H}_{2} \mathrm{O}$ into deionized (DI) water and the working solutions were obtained by freshly diluting the arsenic stock solution with DI water.

\section{Preparation of GNP-HCO composite}

A certain amount of GNP was dispersed at a concentration of 0.5 $\mathrm{mg} \mathrm{mL} \mathrm{m}^{-1}$ into ethanol by ultrasonication for at least $30 \mathrm{~min}$. $\mathrm{Ce}\left(\mathrm{NO}_{3}\right)_{3}$ was then added into the solution to bring a concentration of cerium to $0.01 \mathrm{M}$ and stirred at $700 \mathrm{rpm}$ overnight. Thereafter, $0.5 \mathrm{M} \mathrm{NaOH} /$ ethanol solution was added dropwise into the solution under continuous stirring until $\mathrm{pH}=10 \pm 0.1$. Finally, the formed particles were collected, washed sequentially by DI water and ethanol for several times, and then dried in the oven for $12 \mathrm{~h}$ at $70{ }^{\circ} \mathrm{C}$. As a comparison, the HCO was synthesized via a similar route without the addition of GNP.

\section{Characterizations of adsorbent}

Morphology and elemental analysis. The surface morphology of adsorbent was studied using a field emission scanning electron microscope (FESEM) (JSM6700F, JEQ, Japan) equipped with an energy dispersive X-ray spectroscopy (EDX, JEOL JED 2300). The samples were first coated with a thin film of platinum on the surface for electrical conductive purpose. The morphology of the adsorbents was further analyzed by the transmission electron microscopy (TEM) (JEOL JEM-2100).

Determination of point of zero charge. The point of zero charge $\left(\mathrm{pH}_{\mathrm{PZC}}\right)$ was estimated by the $\mathrm{pH}$ drift method. ${ }^{29}$ The adsorbent was first suspended in $0.01 \mathrm{M} \mathrm{NaNO}_{3}$ for $24 \mathrm{~h}$, after which the $\mathrm{pH}$ change became insignificant. $50 \mathrm{~mL}$ suspension was then adjusted to a series of $\mathrm{pH}$ values using either $\mathrm{NaOH}$ or $\mathrm{HNO}_{3}$ solution. After agitation for $60 \mathrm{~min}$ to achieve equilibrium, the initial $\mathrm{pH}$ was measured; then $1.5 \mathrm{~g} \mathrm{NaNO}{ }_{3}$ was added to each suspension solution to bring final electrolyte concentration to approximately $0.45 \mathrm{M}$. After another $3 \mathrm{~h}$, the final $\mathrm{pH}$ was measured. The results, plotted as $\Delta \mathrm{pH}$ (final $\mathrm{pH}-$ initial $\mathrm{pH}$ ) against final $\mathrm{pH}$, yielded the $\mathrm{pH}_{\mathrm{PZC}}$ as the $\mathrm{pH}$ at which $\Delta \mathrm{pH}$ equals to 0 .

\section{Adsorption experiment}

Adsorption kinetics. The adsorption kinetics experiment was carried out at initial arsenic concentration ([As $\left.]_{0}\right)$ of $10 \mathrm{mg} \mathrm{L}^{-1}$ and the adsorbent dosage $(\mathrm{m})$ of $0.1 \mathrm{~g} \mathrm{~L}^{-1}$. The solution $\mathrm{pH}$ value was controlled at 4.0 during the adsorption process. The samples were taken at different time intervals and the experiments were completed in at least duplicate. The mean values were present and used for modelling study. After filtering with $0.45 \mu \mathrm{m}$ cellulose membrane (Whatman, Sigma-Aldrich), the arsenic concentration was measured by an inductively coupled plasma optical emission spectrometer (ICP-OES, Perkin-Elmer Optima 3000).

Influence of $\mathbf{~ p H}$ and competitive factors. The experiment on $\mathrm{pH}$ effect was conducted with an initial arsenic concentration of $10 \mathrm{mg} \mathrm{L}^{-1}$, and solution $\mathrm{pH}$ values were adjusted from 3 to 10 by adding a certain amount of $\mathrm{HNO}_{3}$ and/or $\mathrm{NaOH}$. The adsorption experiment was conducted at room temperature $\left(T=25 \pm 1{ }^{\circ} \mathrm{C}\right)$ for $12 \mathrm{~h}$. Other procedures were the same as that of kinetics experiment.

The presence of competitive factors such as $\mathrm{HA}, \mathrm{NaF}, \mathrm{Na}_{2} \mathrm{SO}_{4}$, $\mathrm{NaHCO}_{3}$ or $\mathrm{KH}_{2} \mathrm{PO}_{4}$ in the water may affect the adsorption performance as well. These substances were respectively added into the arsenic solution to study their influence on the arsenic uptake. The procedures were the same as that used in the $\mathrm{pH}$ effect study, except that the $\mathrm{pH}$ was fixed at 4.0.

Adsorption isotherm. Experiments for studying arsenic adsorption isotherm were conducted at room temperature and $\mathrm{pH} 4.0$ and 7.0 by following the kinetics procedures. $0.01 \mathrm{~g}$ adsorbent was added to $100 \mathrm{~mL}$ arsenic solution with concentrations ranging from 1 to $80 \mathrm{mg} \mathrm{L}^{-1}$.

Performance in surface water. To evaluate the arsenic removal performance in surface water, the Singapore reservoir water was employed (the water characteristics can be found in Table $\mathrm{S} 1 \dagger$ ) to study the removal efficiency of arsenic under different adsorbent dosages. In the experiment, $\mathrm{Na}_{2} \mathrm{HAsO}_{4}$ was spiked into the water sample so that the concentration of 100 $\mu \mathrm{g}-\mathrm{As} \mathrm{L}^{-1}$ can be obtained, which represents a typical situation of arsenic contaminated surface water. After adsorption with various amounts of adsorbent, the removal efficiency of arsenic was measured with ICP-OES.

\section{XPS analysis}

The surface of adsorbents before and after arsenic adsorption was analyzed by an X-ray photoelectron spectroscopy (XPS) (Kratos AXIS Ultra ${ }^{\text {DLD }}$, Kratos Analytical Ltd). The XPS results were collected in binding energy forms and fitted using a nonlinear least-square curve fitting program (XPSPEAK41 Software). To compensate for the charging effect, all spectra were calibrated with graphitic carbon as reference at a binding 
energy of $284.8 \mathrm{eV}$. For the elements of cerium and oxygen, the spectra were deconvolved with the subtraction of a linear background and a Gaussian (20\%)-Lorentzian (80\%) mixed function.

\section{Results and discussion}

\section{Characterizations of adsorbent}

The surface morphology and element distribution of the assynthesized GNP-HCO adsorbent were characterized by FESEM (inset) and EDS analysis, as displayed in Fig. 1a. The aggregation of the GNP-HCO particles was observed because the heat drying was applied into the synthesis process of adsorbents. It is evident that a dense particle layer was formed on the surface of GNP, which consisted nano-sized spherical particles (Fig. S1 $\dagger$ ). On the basis of the EDS spectrum, cerium (Ce) element can be detected from the GNP-HCO adsorbent, which indicates that HCO has been successfully coated on the surface of GNP.

The value of point of zero charge $\left(\mathrm{pH}_{\mathrm{PzC}}\right)$ of the adsorbent is determined to be approximately 6.0 (Fig. 1b). The surface charge of the adsorbent highly depends on the solution $\mathrm{pH}$. When the solution $\mathrm{pH}$ is above its $\mathrm{pH}_{\mathrm{PZC}}$, negative charges can be readily formed on the surface of the adsorbent, which is unfavorable for the uptake of anion because of the enhanced electrostatic repulsion between the adsorbent surface and the target anions. In contrast, the adsorbent would be positively charged at $\mathrm{pH}<\mathrm{pH}_{\mathrm{PZC}}$, which is favorable for the efficient arsenic uptake.
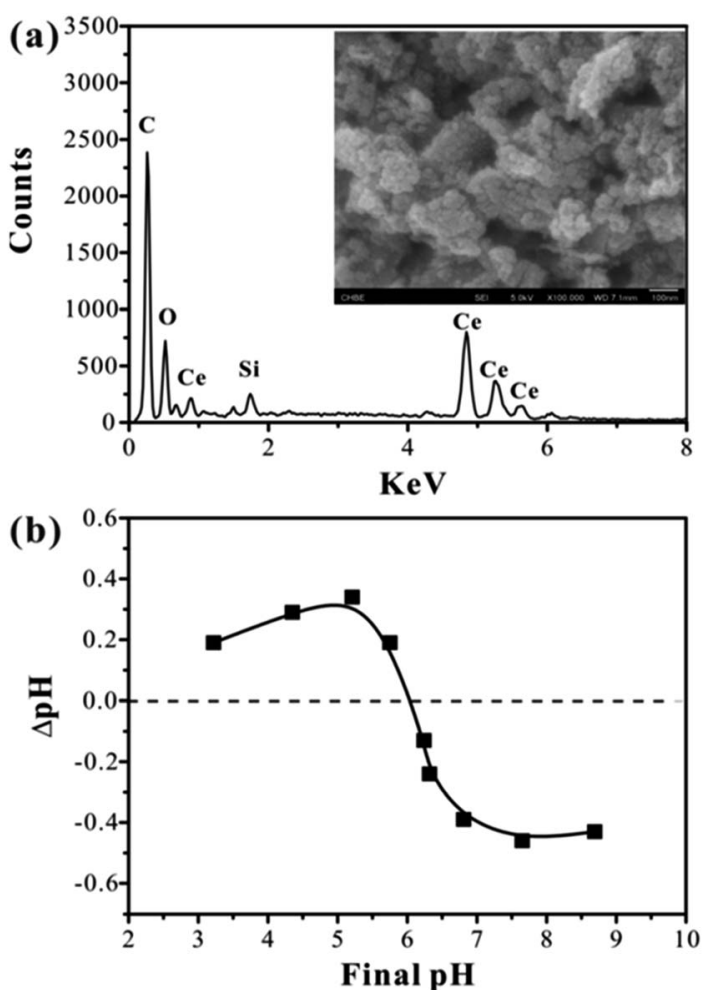

Fig. 1 Characterization of the GNP-HCO adsorbent: (a) FESEM (inset) and EDS analysis; (b) point of zero charge.

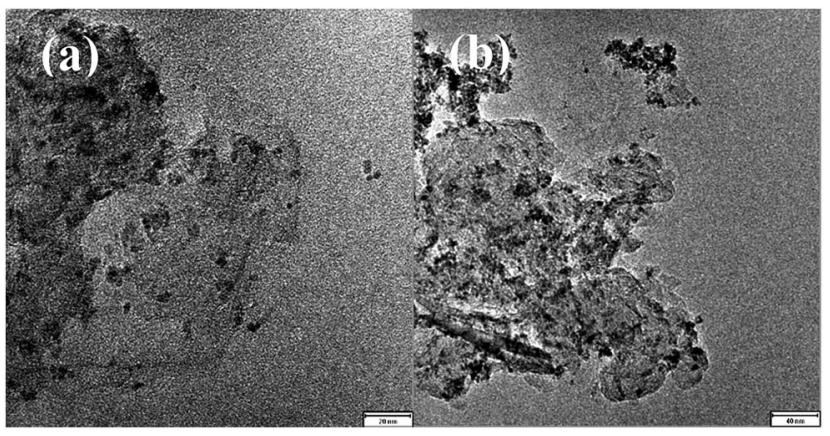

Fig. 2 TEM images of the GNP-HCO adsorbent before (a) and after (b) As-loaded.

TEM analysis was further conducted to examine the change of the morphology of the GNP-HCO adsorbent before and after arsenic loading, as shown in Fig. 2. It is clearly seen that the highly transparent carbon sheet is decorated randomly by the deep-coloured particles with the size of $\sim 10 \mathrm{~nm}$, indicating that the nano-sized HCO particles have been uniformly loaded on the surface of the GNP. After the adsorption, there is no obvious change in the structure of the GNP-HCO adsorbent. The highly dispersed nanoparticles on the thin GNP layer would be beneficial for the adsorption process compared to the pure $\mathrm{HCO}$ particle. As well known, the aggregation phenomenon widely occurs in the preparation of metal oxide nanoparticles due to their high surface energy.

\section{Adsorption kinetics}

An extremely rapid adsorption behavior of arsenate onto the GNP-HCO adsorbent can be observed in Fig. 3. About $88.3 \%$ of equilibrium adsorption capacity of GNP-HCO can even be achieved within the first $20 \mathrm{~min}$, with an initial arsenate concentration of $10 \mathrm{mg} \mathrm{L}^{-1}$. This finding is attractive for actual application because rapid adsorption rate at solid-solution interface may significantly reduce the required retention time in adsorption module as well as the cost of construction and operation.

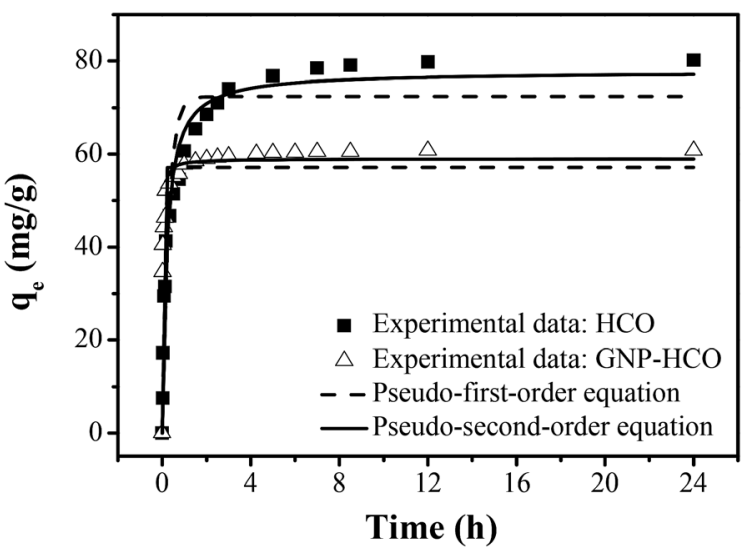

Fig. 3 Adsorption kinetics of arsenate. $[\mathrm{As}(\mathrm{V})]_{0}=10 \mathrm{mg} \mathrm{L}^{-1}, m=0.1 \mathrm{~g}$ $\mathrm{L}^{-1}$, and $\mathrm{pH}=4.0$. 
It is also worthwhile to note that adsorption rate of GNP$\mathrm{HCO}$ is much higher than that of $\mathrm{HCO}$ and other reported adsorbents, according to the rate constant $\left(k_{1}\right.$ or $\left.k_{2}\right)$ obtained from the models. ${ }^{30-32}$ The equilibrium adsorption of arsenate on GNP-HCO can be achieved within $2 \mathrm{~h}$, while it takes more than 8 $\mathrm{h}$ for HCO alone. This may be due to the planar sheet structure and high surface area of GNP favors the diffusion of arsenate towards the active sites of HCO.

To better understand the adsorption mechanism, two empirical adsorption reaction models of pseudo-first-order model and pseudo-second-order model were applied to simulate the adsorption process. ${ }^{33}$ The pseudo-first-order model is generally expressed as:

$$
\ln \left(q_{\mathrm{e}}-q_{t}\right)=\ln q_{\mathrm{e}}-k_{1} t
$$

The pseudo-second-order model is based on the assumption that the rate of occupation of adsorption sites is proportional to the square of the number of unoccupied sites and can be described as:

$$
\frac{t}{q_{t}}=\frac{1}{k_{2} q_{\mathrm{e}}^{2}}+\frac{t}{q_{\mathrm{e}}}
$$

where $q_{\mathrm{e}}$ and $q_{t}$ are the amount of arsenate adsorbed by adsorbent at equilibrium and time $t\left(\mathrm{mg} \mathrm{g}^{-1}\right), k_{1}\left(\mathrm{~h}^{-1}\right)$ and $k_{2}(\mathrm{~g}$ $\mathrm{mg}^{-1} \mathrm{~h}^{-1}$ ) is, respectively, the equilibrium constant of the pseudo-first and pseudo-second models, and $t$ is the adsorption time (h).

The fitting parameters obtained from the kinetic models were summarized in Table 1 . The experimental data can be better described by the pseudo-second-order model with a higher value of correlation coefficient $\left(r^{2}=0.97\right)$. This indicates the adsorption process could be due to chemisorption.

\section{Adsorption equilibrium}

pH effect. The effect of solution $\mathrm{pH}$ on the removal of arsenate was experimentally examined in the $\mathrm{pH}$ range of 3.0-10.0. As shown in Fig. 4a, the uptake of arsenate on the GNP-HCO is slightly enhanced when solution $\mathrm{pH}$ increases from 3.0 to 4.0 , and the maximum adsorption capacity of $61.03 \mathrm{mg}-\mathrm{As}^{-1}$ is obtained at $\mathrm{pH}$ 4.0. The adsorption of arsenate onto the GNPHCO drops when the solution $\mathrm{pH}$ increases further. Note that the adsorption capacity of $45.42 \mathrm{mg}^{-A s} \mathrm{~g}^{-1}$ is still obtained at neutral condition. In contrast, nearly negligible adsorption of arsenate (around $1 \mathrm{mg}$-As $\mathrm{g}^{-1}$ ) was observed for the pristine

Table 1 Parameters of pseudo-first and-second order equations

\begin{tabular}{|c|c|c|c|c|c|c|}
\hline \multirow[b]{2}{*}{ Adsorbent } & \multicolumn{3}{|c|}{ Pseudo-first-order } & \multicolumn{3}{|c|}{ Pseudo-second-order } \\
\hline & $\begin{array}{l}q_{\mathrm{e}} \\
\left(\mathrm{mg} \mathrm{g}^{-1}\right)\end{array}$ & $\begin{array}{l}k_{1} \\
\left(\mathrm{~h}^{-1}\right)\end{array}$ & $r^{2}$ & $\begin{array}{l}q_{\mathrm{e}} \\
\left(\mathrm{mg} \mathrm{g}^{-1}\right)\end{array}$ & $\begin{array}{l}k_{2} \\
\left(\mathrm{~g} \mathrm{mg}^{-1} \mathrm{~h}^{-1}\right)\end{array}$ & $r^{2}$ \\
\hline GNP-HCO & 57.17 & 40.87 & 0.89 & 58.96 & 1.019 & 0.97 \\
\hline $\mathrm{HCO}$ & 72.38 & 3.60 & 0.92 & 77.75 & 0.066 & 0.98 \\
\hline
\end{tabular}
$\left([\mathrm{As}]_{0}=10 \mathrm{mg} \mathrm{L}^{-1}\right)$
GNP. As expressed in section Introduction, the GNP is more effective to remove organic pollutants from water and the loaded HCO nano-sized particles should be responsible for the highly efficient uptake of arsenate.

Based on the modeling result from MINEQL, $\mathrm{H}_{2} \mathrm{AsO}_{4}{ }^{-}$and $\mathrm{HAsO}_{4}{ }^{2-}$ are the dominant arsenate species in $\mathrm{pH}$ ranging from 3 to 10 . The electrostatic interaction between the active sites on the adsorbent and arsenate may play an important role in the adsorption process. Since the $\mathrm{pH}_{\mathrm{PzC}}$ of the adsorbent is determined to be $\sim 6.0$ (shown in Fig. $1 \mathrm{~b}$ ), stronger protonation of the functional groups on the surface of adsorbent can be achieved at $\mathrm{pH}<6.0$, leading to enhanced electrostatic attraction between the positively charged active sites of the adsorbent and the negatively charged arsenate. However, the surface of the adsorbent becomes negative at $\mathrm{pH}>6.0$ and, hence, the electrostatic repulsion effect would significantly hinder the uptake of arsenate. Furthermore, more $\mathrm{OH}^{-}$species are likely to present in the solution with the increase in solution $\mathrm{pH}$ and thus compete with arsenic towards the active sites of adsorbent.

Effect of competitive factors. Since competitive anions such as bicarbonate, sulfate, phosphate fluoride, and natural organic matter (NOM) generally co-exist in natural water and groundwater, it is important to investigate the effects of their presence on arsenate adsorption. In this study, humic acid (HA) was
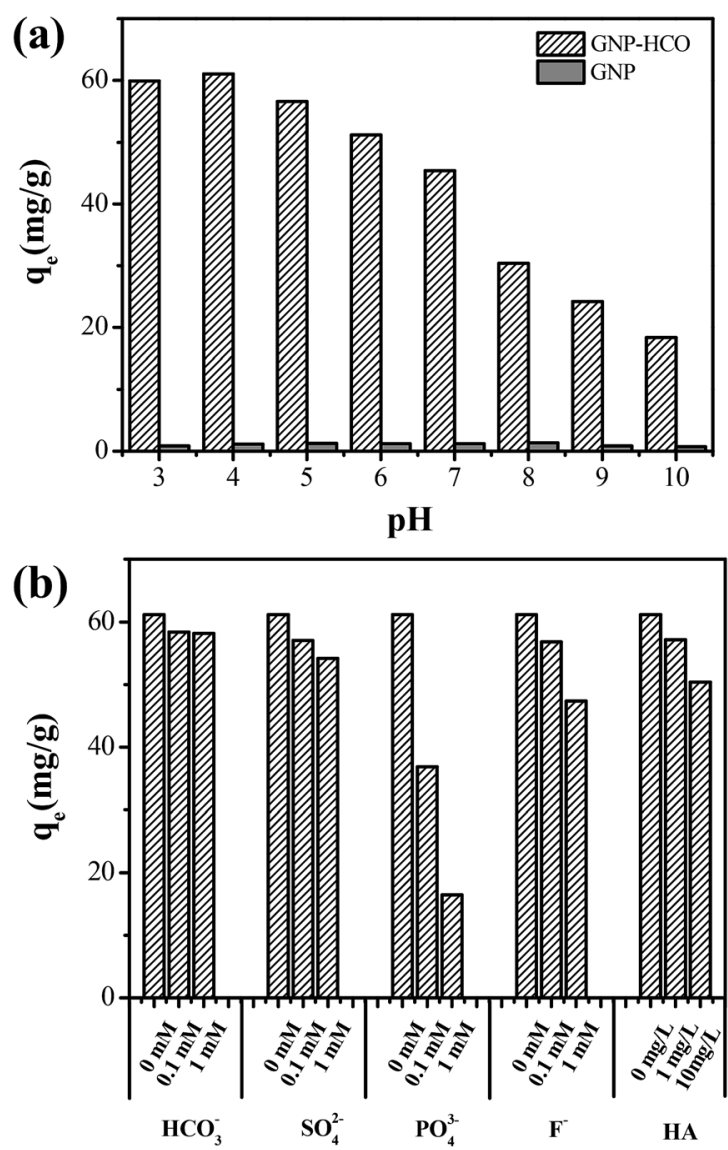

Fig. 4 Effects of solution $\mathrm{pH}$ (a) and co-existing anions and humic acid (b) on the arsenate adsorption: $[\mathrm{As}(\mathrm{v})]_{0}=10 \mathrm{mg} \mathrm{L}^{-1}, m=0.1 \mathrm{~g} \mathrm{~L}^{-1}, \mathrm{pH}$ $=4.0$ for (b), $t=12 \mathrm{~h}, T=25 \pm 1{ }^{\circ} \mathrm{C}$. 
chosen as a representative of NOM due to the prevalence of humic-like substances in surface waters and wastewater effluent. As shown in Fig. 4b, the presence of these competitive anions and HA has shown certain interferences on the arsenate adsorption. For example, the $q_{\mathrm{e}}$ at the presence of $1 \mathrm{mg} \mathrm{L}^{-1}$ and $10 \mathrm{mg} \mathrm{L}^{-1}$ HA was decreased by $7-18 \%$ in comparison with that obtained at their absence. Especially, a seriously negative effect on the adsorption of arsenate was observed in the presence of phosphate in solution. Similar adsorption behaviors of phosphate and arsenate may be due to the fact that they are both in the form of triprotic acid, and with similar ionization constants. ${ }^{32}$ Many previous studies have reported the strong competition between arsenate and phosphate during the adsorption process. ${ }^{34-37}$ However, it is noted that in the present study, when the concentration of phosphate in solution reaches $1 \mathrm{mM}$, nearly ten times of arsenate concentration $(0.13 \mathrm{mM})$, an adsorption capacity of $16.47 \mathrm{mg}^{-A s \mathrm{~g}^{-1}}$ can still be obtained.

Adsorption isotherm. The adsorption isotherm was conducted at $\mathrm{pH} 4.0$ and 7.0, and the modelling results from both Langmuir and Freundlich are shown in Fig. 5, and the related parameters are summarized in Table 2. Langmuir equation seems to work better in the description of experimental data. This further indicates that arsenate uptake is mainly controlled by a monolayer adsorption process. ${ }^{38,39}$ The maximum adsorption capacities of arsenate calculated by the Langmuir model are 62.33 and $41.31 \mathrm{mg}$-As $\mathrm{g}^{-1}$ under $\mathrm{pH} 4.0$ and 7.0, respectively. As shown by a control adsorption experiment, there is no obvious adsorption of arsenic observed on virgin GNP $(<0.5 \mathrm{mg}-$ As $\mathrm{g}^{-1}$ ). Thus, the promising adsorption capacity of GNP-HCO adsorbent could be mainly attributed to the loading of the HCO. It is worthwhile to note that the effluent concentration of arsenate would meet the guideline of arsenic in drinking water (i.e. $10 \mu \mathrm{g} \mathrm{L}^{-1}$ ) with an initial arsenate concentration of below 2 $\mathrm{mg} \mathrm{\textrm {L } ^ { - 1 }}$ at neutral $\mathrm{pH}$ condition. The excellent performance on the removal of arsenate further indicates its promising potential for the treatment of arsenic-contaminated drinking water. After the adsorption completed, the spent adsorbent was tried to be regenerated by soaking into strong base solution $(0.1 \mathrm{M}$ $\mathrm{NaOH}$ ) for $1 \mathrm{~h}$. However, the adsorption capacity of reused adsorbent was found much less than that of fresh adsorbent, e.g. the $q_{\mathrm{e}}$ has decreased by $72 \%$ (first time) and $84 \%$ (second time) after regenerated and reused, as displayed in Fig. S3. $\uparrow$ The reason for this could be mainly due to the strong affinity of arsenate towards the adsorbent that cannot be easily desorbed and hence the available adsorption sites cannot be fully recovered. This assumption was also supported by the $\mathrm{pH}$ effect study. As shown in Fig. 4a, the adsorption capacities of 24.19 and $18.37 \mathrm{mg}^{-A s} \mathrm{~g}^{-1}$ can be still achieved at $\mathrm{pH} 9$ and $\mathrm{pH} 10$, respectively, which could further confirm the formation of the strong bond between arsenate and the adsorbent. On the other hand, the strong combination of arsenic with the adsorbent could avoid the secondary release of arsenate to water body and good for the practical applications. Also, the agglomeration among the GNP scaffolds caused by the strong $\pi-\pi$ interaction may inevitably sacrifice some active adsorption sites. Hence, more efforts should be devoted to develop other more effective approaches to recover the adsorption ability of the promising adsorbent. Moreover, a comparison of the $q_{\max }$ for arsenate between the as-synthesized GNP-HCO adsorbent and some previously reported carbon based adsorbents are summarized in Table 3. The results demonstrate that the GNP-HCO adsorbent shows much better performance than most previously reported adsorbents, including some modified graphene materials.

Performance in surface water. To further explore the potential of the adsorbent in the treatment of arseniccontaminated surface water, reservoir water was employed to study the arsenate removal under different adsorbent dosages. In the experiment, certain $\mathrm{Na}_{2} \mathrm{HAsO}_{4}$ was spiked into the water samples so that a concentration of $100 \mu \mathrm{g}$-As $\mathrm{L}^{-1}$ can be obtained, which represents a typical concentration of natural water in the risk of arsenic around the world.

As shown in Fig. 6, the arsenate can be effectively removed from reservoir water with relatively low adsorbent dosage, and the removal efficiency increases with the adsorbent dosage. For example, at an adsorbent dosage of $15 \mathrm{mg} \mathrm{L}^{-1}$, the arsenate concentration in effluent can be lower than $10 \mu \mathrm{g} \mathrm{L}^{-1}$, which meets the maximum contaminant level for arsenic in drinking water, and with a corresponding adsorption capacity of $6.4 \mathrm{mg}$ As $\mathrm{g}^{-1}$. Therefore, the GNP-HCO adsorbent exhibits very high practical application potential in the arsenate removal from surface water.
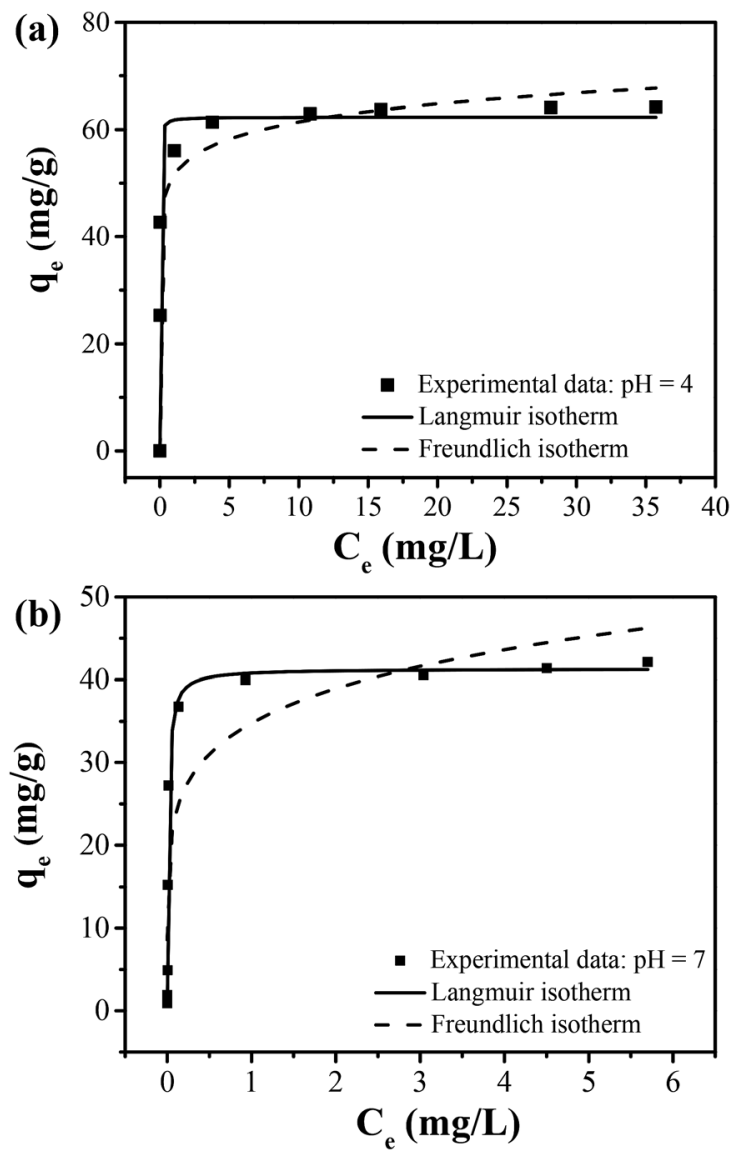

Fig. 5 Adsorption isotherms of arsenate on the adsorbent: (a) $\mathrm{pH}=$ 4.0; (b) $\mathrm{pH}=7.0 . \mathrm{m}=0.1 \mathrm{~g} \mathrm{~L}^{-1}, t=12 \mathrm{~h}, T=25 \pm 1{ }^{\circ} \mathrm{C}$. 
Table 2 Langmuir and Freundlich isotherms for arsenate adsorption

\begin{tabular}{lllllllll}
\hline & \multicolumn{2}{l}{ Langmuir isotherm } & & \multicolumn{3}{c}{ Freundlich isotherm } \\
\cline { 2 - 4 } $\mathrm{pH}$ & $q_{\max }\left(\mathrm{mg} \mathrm{g}^{-1}\right)$ & $B\left(\mathrm{~L} \mathrm{mg}^{-1}\right)$ & $r^{2}$ & & $K_{\mathrm{f}}\left(\mathrm{L} \mathrm{g}^{-1}\right)$ & $n$ & $r^{2}$ \\
\hline 4.0 & 62.33 & 110.80 & 0.978 & 51.44 & 13.00 & 0.941 \\
7.0 & 41.31 & 78.20 & 0.970 & 34.76 & 6.106 & 0.795
\end{tabular}

\section{XPS analysis}

The adsorption mechanism of arsenate onto GNP-HCO adsorbent was further studied by the XPS analysis. The XPS wide scan spectra of both virgin and As-loaded adsorbents are shown in Fig. S2. $\dagger$ The appearance of characteristic peaks of arsenic includes As 3d, As 3s and As LMM after the adsorption, indicating that arsenate has been successfully adsorbed. Furthermore, the peaks of Ce $4 \mathrm{~d}$, Ce $\mathrm{MN}$ and Ce $3 \mathrm{~d}$ are also detected on the surface of both virgin and As-loaded adsorbents.

As shown in Fig. 7, the high-resolution XPS spectra of Ce 3d before and after arsenate adsorption mainly consist of the spinorbit splitting of Ce $3 d_{5 / 2}$ and Ce $3 d_{3 / 2}$. Each separated peak is further divided into three component peaks due to a redistribution of the entire energy spectrum. The complex XPS spectra of Ce 3d were fitted by software to determine the chemical state of cerium element on the adsorbent according to the method described by Preisler et al. ${ }^{48}$ Six fitting peaks labeled as blue color are determined as characteristic of Ce(Iv), while other two peaks with red color are assigned to the presence of $\mathrm{Ce}(\mathrm{III})$. Therefore, the major chemical state of cerium element on the adsorbent is identified as $+\mathrm{IV}$, which may be due to the occurrence of oxidation reaction during the adsorbent preparation.

As shown in Fig. 8, the high resolution scan of O1s spectra of the adsorbents can be divided into metal oxide (M-O), metalhydroxyl $(\mathrm{M}-\mathrm{OH})$ and adsorbed water $\left(\mathrm{H}_{2} \mathrm{O}\right)$ with the binding energies of 529.68, 531.44 and $532.87 \mathrm{eV}$ (for virgin adsorbent) and 529.77, 531.07 and 532.23 eV (for As-loaded adsorbent), respectively. ${ }^{49-52}$ After the adsorption, a new component peak with binding energy of $533.57 \mathrm{eV}$ can be attributed to arsenicoxygen (As-O) bond. After the adsorption, the relative area ratio for the component peak of $\mathrm{M}-\mathrm{O}$ increases from $32.20 \%$ to

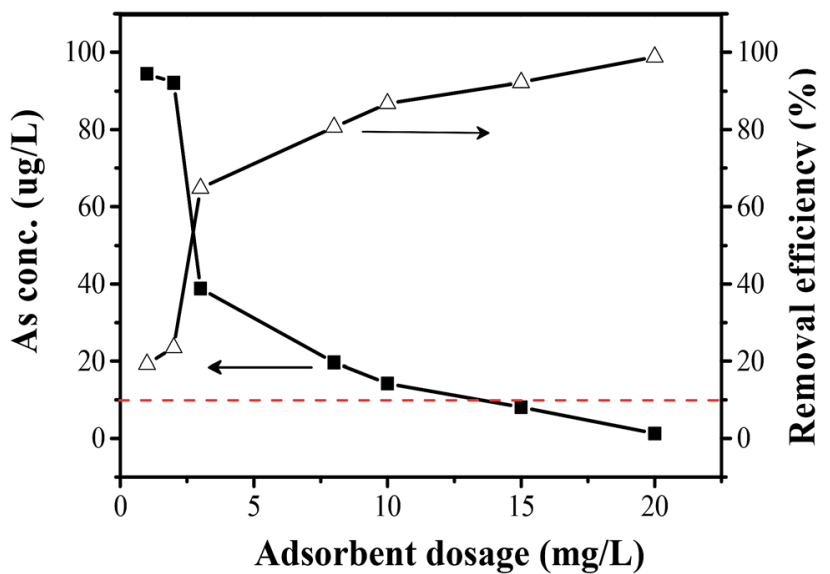

Fig. 6 Arsenate concentrations and removal efficiency of reservoir water sample as a function of adsorbent dosages. [As] $]_{0}=100 \mu \mathrm{g} \mathrm{L}^{-1}$, $\mathrm{pH}=6.78$

$46.12 \%$, while the relative area ratios for the peaks due to $\mathrm{M}-\mathrm{OH}$ and $\mathrm{H}_{2} \mathrm{O}$ decrease from $34.33 \%$ to $27.75 \%$ and $33.47 \%$ to $16.72 \%$, respectively. The significant decrease in the area ratio of $\mathrm{M}-\mathrm{OH}$ group indicates that $-\mathrm{OH}$ groups on the surface of the adsorbent may play a certain role for the arsenate adsorption.

The atomic ratios of $\mathrm{Ce}, \mathrm{O}$ and As in the adsorbents before and after adsorption are listed in Table S2. $\dagger$ The atomic faction of the arsenic is increased from $0 \%$ to $2.95 \%$ after adsorption process. This indicates that the arsenic can be adsorbed onto the GNP-HCO adsorbent. Meanwhile, the atomic fraction of $\mathrm{O}$ decreases remarkably from $77.52 \%$ to $65.40 \%$ after the adsorption. This change further supports the involvement of hydroxyl group in the adsorption process.

Based on the previous results and analysis, the hydroxyl groups of HCO play a significant role in the arsenic removal, and a possible adsorption mechanism of GNP-HCO was proposed, as display in Fig. 9. The $\mathrm{M}-\mathrm{OH}$ group on the surface of the adsorbent may be protonated at acidic condition which causes an enhanced electrostatic attraction between arsenate and active sites, followed by the occurrence of binding of arsenate on the active sites, and then displaced from the metal

Table 3 Comparison of maximum adsorption capacities for different adsorbents

\begin{tabular}{llll}
\hline Adsorbent & $\begin{array}{l}\text { Initial As conc. } \\
\left(\mathrm{mg} \mathrm{L}^{-1}\right)\end{array}$ & $\begin{array}{l}\text { Adsorbent dosage } \\
\left(\mathrm{g} \mathrm{L}^{-1}\right)\end{array}$ & $\begin{array}{l}\text { Max. As(v) adsorption capacity } \\
\left(\mathrm{mg} \mathrm{g}^{-1}\right)\end{array}$ \\
\hline Iron hydroxide modified AC & $0-1.5$ & 0.75 & 1.25 \\
Manganese-modified ACF & $1.4-80$ & 0.80 & 23.77 \\
$\mathrm{Fe}_{3} \mathrm{O}_{4}$-MWNTs based electrodes & $200-400$ & 0.08 & 53 \\
$\mathrm{Fe}_{3} \mathrm{O}_{4}$-graphene-MnO $\mathrm{M}_{2}$ composites & $0.01-10$ & 0.50 & 12.22 \\
$\mathrm{Cu}_{2} \mathrm{O}-$-reduced graphene oxide & $0.25-2$ & 0.09 & 4.807 \\
Magnetite-reduced graphitic oxide & $3-7$ & 0.2 & 5.83 \\
Magnetic graphene oxide & $10-60$ & 0.4 & 59.6 \\
TiO & $0.1-10$ & 0.31 & 14.1 \\
Zircoated CNT filter & $0-0.12$ & 0.03 & 8.95 \\
Zero-valent iron modified AC & 2 & $0.5-6$ & 12.02 \\
GNP-HCO & $1-80$ & 0.1 & 62.33
\end{tabular}




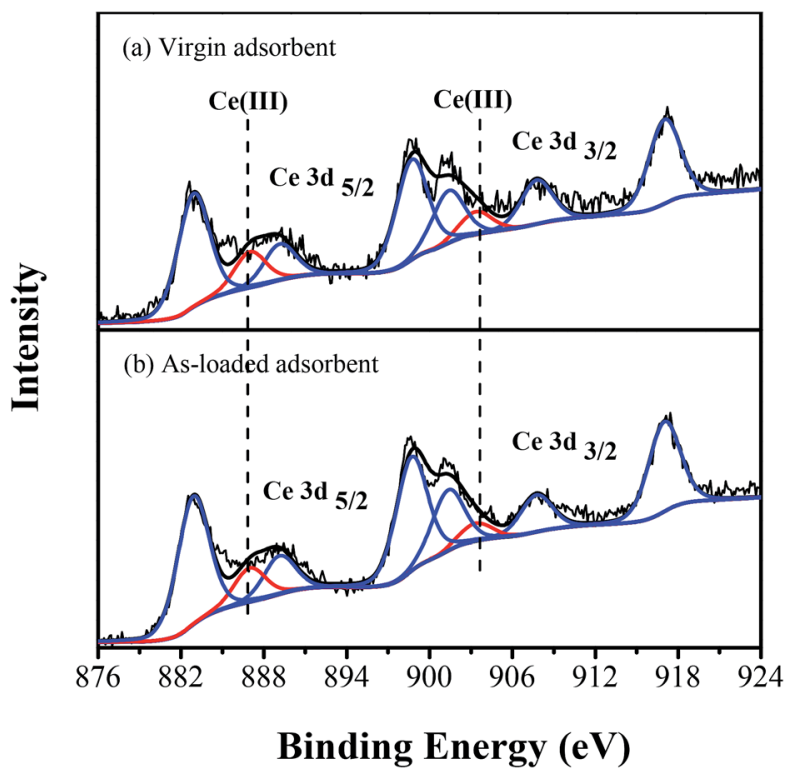

Fig. 7 XPS spectra of Ce $3 d$ of the adsorbents: (a) virgin adsorbent; (b) As-loaded adsorbent.

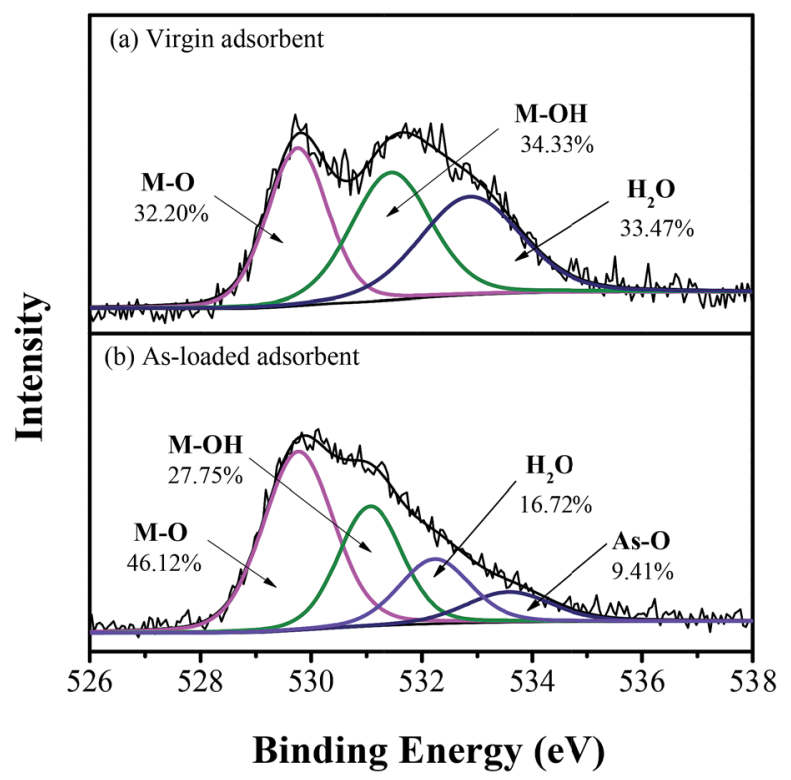

Fig. 8 XPS spectra of $O 1$ s of the adsorbents: (a) virgin adsorbent; (b) As-loaded adsorbent.

binding sites. It is found that the positively charged group is much easier to be substituted than the neutral group which is more favorable to the ligand exchange process. ${ }^{53}$ With the increase in solution $\mathrm{pH}$, more hydroxyl groups will be present leading to a stronger competition for the active sites. In parallel, the surface charge of the adsorbent would become more negative and the strong electrostatic repulsion between the active sites and arsenic species would thus hinder the ligands exchange and finally reduce the adsorption capacity.

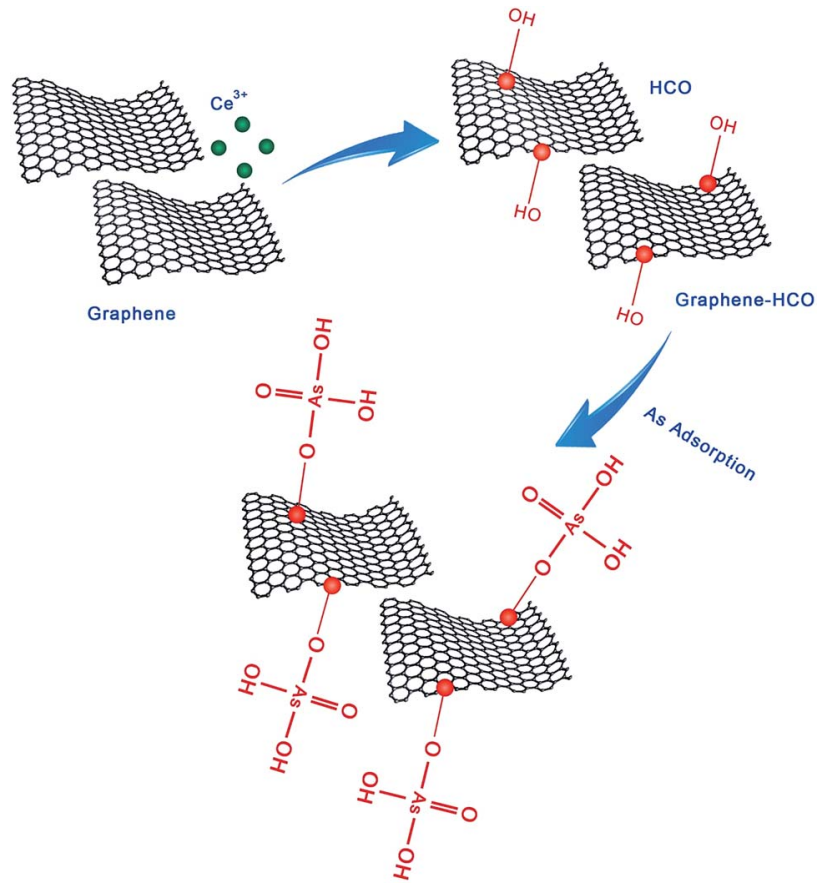

Fig. 9 Schematic diagram of adsorption mechanism of arsenate onto GNP-HCO.

\section{Conclusions}

Hydrous cerium oxide modified graphene was prepared for the removal of arsenic from aqueous solution. The rapid adsorption kinetics and excellent adsorbing capability of GNP-HCO adsorbent provide convincing evidence for its potential use in the treatment of arsenic-contaminated water.

\section{Acknowledgements}

The authors acknowledge the financial support from the GENUS Research Grant (WBS Number of R-706-005-004-592).

\section{References}

1 H. Brammer and P. Ravenscroft, Environ. Int., 2009, 35, 647654.

2 M. M. Karim, Water Res., 2000, 34, 304-310.

3 P. Pal, S. Ahammad, A. Pattanayak and P. Bhattacharya, Water Environ. Res., 2007, 79, 357-366.

4 W. H. Ficklin, Talanta, 1983, 30, 371-373.

5 D. Pokhrel, Removal of Arsenic from Drinking Water by Fungal Biomass and Biological Filtration, University of Regina, Canada, 2007.

6 S. M. Miller, M. L. Spaulding and J. B. Zimmerman, Water Res., 2011, 45, 5745-5754.

7 E. Fogarassy, I. Galambos, E. Bekassy-Molnar and G. Vatai, Desalination, 2009, 240, 270-273.

8 K. Sasaki, H. Nakano, W. Wilopo, Y. Miura and T. Hirajima, Colloids Surf., A, 2009, 347, 8-17. 
9 N. Horzum, M. M. Demir, M. Nairat and T. Shahwan, RSC Adv., 2013, 3, 7828-7837.

10 M. Asadullah, I. Jahan, M. B. Ahmed, P. Adawiyah, N. H. Malek and M. S. Rahman, J. Ind. Eng. Chem., 2014, 20, 887-896.

11 S. Lunge, S. Singh and A. Sinha, J. Magn. Magn. Mater., 2014, 356, 21-31.

12 T. Zhang and D. D. Sun, Chem. Eng. J., 2013, 225, 271-279.

13 R. Srivastava, J. Colloid Interface Sci., 2010, 348, 600-607.

14 G. Jegadeesan, S. R. Al-Abed, V. Sundaram, H. Choi, K. G. Scheckel and D. D. Dionysiou, Water Res., 2010, 44, 965-973.

15 H. Cui, Y. Su, Q. Li, S. Gao and J. K. Shang, Water Res., 2013, 47, 6258-6268.

16 S. Bibi, A. Farooqi, K. Hussain and N. Haider, J. Cleaner Prod., 2015, 87, 882-896.

17 Suhas, P. J. M. Carrott and M. M. L. Ribeiro Carrott, Bioresour. Technol., 2007, 98, 2301-2312.

18 H. S. Park, J. R. Koduru, K. H. Choo and B. Lee, J. Hazard. Mater., 2015, 286, 315-324.

19 H. Humbert, H. Gallard, H. Suty and J. P. Croué, Water Res., 2008, 42, 1635-1643.

20 T. Anumol, M. Sgroi, M. Park, P. Roccaro and S. A. Snyder, Water Res., 2015, 76, 76-87.

21 R. K. Joshi, P. Carbone, F. C. Wang, V. G. Kravets, Y. Su, I. V. Grigorieva, H. A. Wu, A. K. Geim and R. R. Nair, Science, 2014, 343, 752-754.

22 K. S. Novoselov, A. K. Geim, S. V. Morozov, D. Jiang, Y. Zhang, S. V. Dubonos, I. V. Grigorieva and A. A. Firsov, Science, 2004, 306, 666-669.

23 J. Zhao, Z. Wang, Q. Zhao and B. Xing, Environ. Sci. Technol., 2014, 48, 331-339.

24 Y. Liu, J. H. Dustin Lee, Q. Xia, Y. Ma, Y. Yu, L. Y. Lanry Yung, J. Xie, C. N. Ong, C. D. Vecitis and Z. Zhou, J. Mater. Chem. A, 2014, 2, 16554-16562.

25 F. Bonaccorso, L. Colombo, G. Yu, M. Stoller, V. Tozzini, A. C. Ferrari, R. S. Ruoff and V. Pellegrini, Science, 2015, 347(6217), 1246501.

26 Z. Liu, K. Parvez, R. Li, R. Dong, X. Feng and K. Müllen, Adv. Mater., 2015, 27, 669-675.

27 L. Qiu, Q. Wu, Z. Yang, X. Sun, Y. Zhang and H. Peng, Small, 2015, 11, 1150-1155.

28 S. C. Ray, in Applications of Graphene and Graphene-Oxide Based Nanomaterials, ed. S. C. Ray, William Andrew Publishing, Oxford, 2015, pp. 1-38.

29 W. Zhang, J. Fu, G. Zhang and X. Zhang, Chem. Eng. J., 2014, 251, 69-79.
30 X. Luo, C. Wang, S. Luo, R. Dong, X. Tu and G. Zeng, Chem. Eng. J., 2012, 187, 45-52.

31 V. Chandra, J. Park, Y. Chun, J. W. Lee, I. C. Hwang and K. S. Kim, ACS Nano, 2010, 4, 3979-3986.

32 Y. Zhang, M. Yang and X. Huang, Chemosphere, 2003, 51, 945-952.

33 Y. S. Ho and G. McKay, Water Res., 2000, 34, 735-742.

34 H. Cui, Q. Li, S. Gao and J. K. Shang, J. Ind. Eng. Chem., 2012, 18, 1418-1427.

35 X. J. Gong, W. G. Li, D. Y. Zhang, W. B. Fan and X. R. Zhang, Int. Biodeterior. Biodegrad., 2015, 102, 256-264.

36 C. Shan and M. Tong, Water Res., 2013, 47, 3411-3421.

37 A. Gupta, V. S. Chauhan and N. Sankararamakrishnan, Water Res., 2009, 43, 3862-3870.

38 X. Song, Y. Zhang, C. Yan, W. Jiang and C. Chang, J. Colloid Interface Sci., 2013, 389, 213-219.

39 I. Langmuir, J. Am. Chem. Soc., 1918, 40, 1361-1403.

40 A. V. Vitela-Rodriguez and J. R. Rangel-Mendez, J. Environ. Manage., 2013, 114, 225-231.

41 Z. Sun, Y. Yu, S. Pang and D. Du, Appl. Surf. Sci., 2013, 284, 100-106.

42 A. K. Mishra and S. Ramaprabhu, J. Phys. Chem. C, 2010, 114, 2583-2590.

43 S. P. Dubey, T. T. M. Nguyen, Y.-N. Kwon and C. Lee, J. Ind. Eng. Chem., 2015, DOI: 10.1016/j.jiec.2015.04.008.

44 G. Sheng, Y. Li, X. Yang, X. Ren, S. Yang, J. Hu and X. Wang, RSC Adv., 2012, 2, 12400-12407.

45 H. Liu, K. Zuo and C. D. Vecitis, Environ. Sci. Technol., 2014, 48, 13871-13879.

46 R. Sandoval, A. M. Cooper, K. Aymar, A. Jain and K. Hristovski, J. Hazard. Mater., 2011, 193, 296-303.

47 H. Zhu, Y. Jia, X. Wu and H. Wang, J. Hazard. Mater., 2009, 172, 1591-1596.

48 E. J. Preisler, O. J. Marsh, R. A. Beach and T. C. McGill, J. Vac. Sci. Technol., B, 2001, 19, 1611-1618.

49 B. Chen, Z. Zhu, J. Ma, Y. Qiu and J. Chen, J. Mater. Chem. A, 2013, 1, 11355-11367.

50 T. Wang, W. Yang, T. Song, C. Li, L. Zhang, H. Wang and L. Chai, RSC Adv., 2015, 5, 50011-50018.

51 Z. Wen, C. Dai, Y. Zhu and Y. Zhang, RSC Adv., 2015, 5, 40584068.

52 S. Guo, W. Sun, W. Yang, Q. Li and J. K. Shang, RSC Adv., 2015, 5, 53280-53288.

53 N. I. Chubar, V. A. Kanibolotskyy, V. V. Strelko, G. G. Gallios, V. F. Samanidou, T. O. Shaposhnikova, V. G. Milgrandt and I. Z. Zhuravlev, Colloids Surf., A, 2005, 255, 55-63. 